\title{
Estadística para la investigación (ISBN 978-9929-620-22-3)
}

\author{
Statistics for research (ISBN 978-9929-620-22-3) \\ Gerardo Arroyo \\ Universidad de San Carlos de Guatemala, Guatemala
}

*Autor al que se dirige la correspondencia: gerarroyo@gmail.com

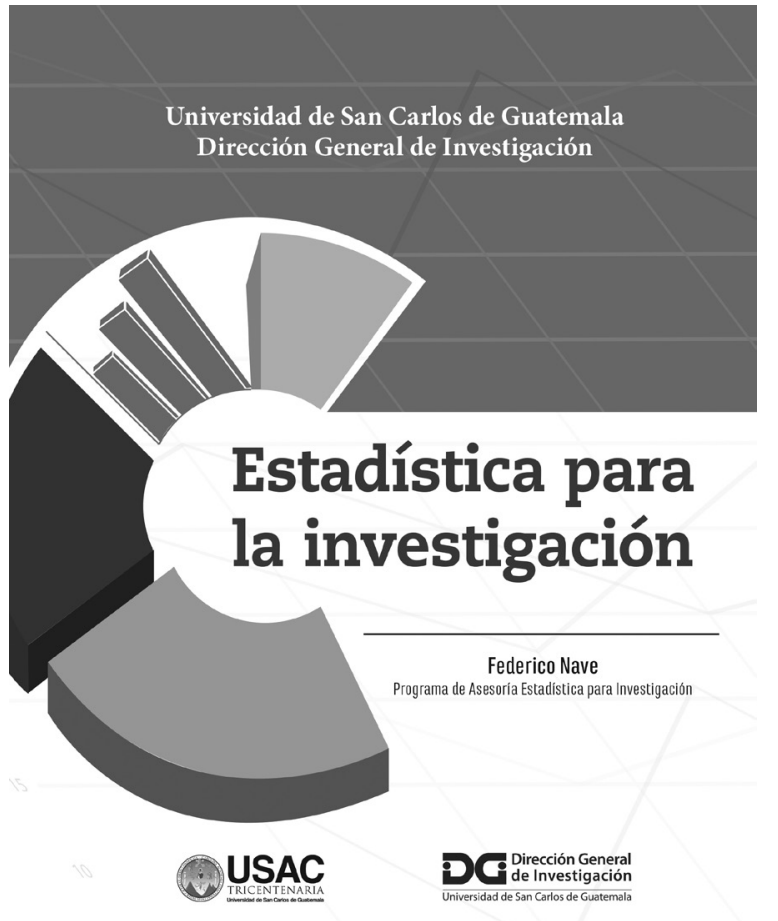

La aplicación de la estadística es fundamental para el diseño, análisis e interpretación de la información en las diversas formas que tiene la ciencia de realizar sus investigaciones. En esta oportunidad tengo el agrado de presentar esta reseña sobre el libro Estadística para la investigación de mi amigo y colega Federico Nave, el cual es una compilación valiosa de artículos publicados, en su mayoría, en el Boletín de Investigación y Posgrado de la Universidad de San Carlos de Guatemala.

La invitación inicial que se hiciera a Federico Nave para que escribiera un artículo sobre estadística en el boletín divulgativo de la Digi obtuvo una respuesta inmediata, entusiasta y constante, que llevó a que en todos, menos en tres de ellos, contáramos con un artículo de diferentes temáticas. El libro tiene además artículos inéditos que complementan una colección original de importante valor académico.

La forma de abordar los temas es también poco tradicional, quizás influenciada por el inicio de la escritura de los temas, que fue de artículos divulgativos para un boletín. Sin embargo, esta misma peculiaridad, hace que el enfoque sea mucho más atractivo para el lector interesado para entender con claridad, los conceptos estadísticos más importantes. A diferencia de un texto tradicional, usualmente plagado de fórmulas y números, el autor nos enseña conceptos y reflexiones, con ejemplos prácticos, que hacen fácil entender y aplicar la estadística.

Nave coordina desde hace cuatro años, el Programa Universitario de Asesoría Estadística para Investigación, y su dedicación al trabajo, disciplina académica y sencillez, lo han convertido en una pieza clave en la investigación que gestiona la Digi. La visión de los investigadores ha cambiado para mejorar. Ahora entienden la importancia del soporte estadístico en los proyectos de investigación, incluso en el área de investigación cualitativa donde no hace mucho, hablar de estadística 
era impensable. Otra área en que la aplicación de los amplios conocimientos de Nave ha sido determinante, es el apoyo en la publicación de artículos científicos en las Revistas Centroamericanas de Investigación y Postgrado, Ciencia, Tecnología y Salud y Ciencias Sociales y Humanidades. Todos los artículos, antes de ser enviados a revisión por pares externos, son cuidadosamente revisados por Nave, quien recomienda mejoras para incrementar la calidad de las publicaciones.
Sin lugar a dudas, el, libro que hoy tengo el agrado de reseñar, será bienvenido por la comunidad académica y especialmente por los investigadores, quienes encontrarán una guía práctica para resolver problemas en sus proyectos de investigación científica.

El libro estará disponible a la venta en la Unidad de Publicaciones y Divulgación de la Dirección General de Investigación a precios populares. 